\title{
Cardiac Output and Distribution of Blood Volume in Central and Peripheral Circulations in Hypertensive and Normotensive Man ${ }^{\star}$
}

\author{
MILOS ULRYCH, EDWARD D. FROHLICH, ROBERT C. TARAZI, \\ HARRIET P. DUSTAN, AND IRVINE H. PAGE \\ From the Research Division, Cleveland Clinic, Cleveland, Ohio, U.S.A.
}

Most haemodynamic studies of arterial hypertension have been concerned with cardiac output and peripheral resistance (Page and McCubbin, 1965). Some, additionally, have investigated regional distribution of blood flow and vascular resistances, whereas only a few, dealing with circulation in the extremities, were designed to provide information about the venous segment of the circulation (Wood, 1961; Caliva et al., 1963a, b). These studies of the capacitance segment in hypertension dealt only with regional circulations; there has been no report on the relationships of total blood volume to its distribution between the central and peripheral circulations, to cardiac output, or to systemic arterial pressure in hypertensive patients.

In the absence of heart failure, the distribution of blood between peripheral and cardiopulmonary segments of the circulation should reflect the distensibility and tone of peripheral and pulmonary capacitance beds. Alterations of such factors may well underline the differences in cardiac output found in different types of hypertension. Cardiac output has been shown to be high in mild, juvenile, and renovascular hypertension (Widimský, Fejfarová, and Fejfar, 1957; Finkielman, Worcel, and Agrest, 1965; Bello, Sevy, and Harakal, 1965; Frohlich et al., 1965), but it is not known whether this represents a developmental phase of hypertension or a haemodynamic response to specific stimuli characterizing these types of hypertension. In regard to the latter consideration, our previous studies of renovascular hypertension had shown that high cardiac output was not a reflection of

Received January 15, 1969.

* Supported in part by grants from the National Institutes of Health. blood volume expansion since intravascular volume was, if anything, decreased (Tarazi et al., 1969). The possibility remained that output might be raised through a redistribution of intravascular volume from peripheral veins to the cardiopulmonary capacitance bed, even if total blood volume were diminished. The present study describes the relations among cardiopulmonary blood volume, total blood volume, cardiac output, and arterial blood pressure in normal subjects, in patients with essential hypertension, or with hypertension accompanying renal arterial disease. This was made possible by the recent development of methods for determination of cardiopulmonary blood volume (Taylor et al., 1965; Levinson, Pacifico, and Frank, 1966), which do not involve left atrial catheterization (Schlant et al., 1959; Milnor, Jose, and McGaff, 1960; Dock et al., 1961; Levinson, Frank, and Hellems, 1964; de Freitas et al., 1965).

\section{SuBJeCtS AND MeTHodS}

The subjects in this study consisted of 19 individuals, 6 normotensive volunteers and 13 patients, 7 with essential hypertension, and 6 with hypertension and renal arterial stenosis. ${ }^{\star}$ In all, cardiopulmonary blood

* The volunteers were for the most part aides and technicians and their friends who came from various laboratories and were relatively familiar with some of the techniques used. One was a resident taking a year's training in medicine. To all, the study was explained and the procedure detailed; beyond a small fee paid for the time and inconvenience of the test, no promise was made and no pressure applied. Four of the 5 co-authors had their blood volumes measured with radio-iodinated human serum albumin; in 3, this was repeated more than once and associated with estimation of extracellular fluid volume with radiobromine. The radioactive doses used were well below permissible levels and were approved by the hospital isotope committee. 
volume and central venous pressure as well as cardiac output, heart rate, arterial blood pressure, and total blood volume were obtained. None had cardiac decompensation, severe nephrosclerosis, or apparent primary aldosteronism. Hypertensive patients therefore were classified as World Health Organization stages I or II. Renal arteriography was performed in all patients permitting differentiation between essential and renovascular hypertension.

All investigations were performed in a quiet laboratory in the morning, with the subjects fasting and resting comfortably supine. Catheters were introduced into an antecubital vein and brachial artery by the Seldinger technique (1953), and advanced to the right atrium and innominate artery or aortic arch, respectively, under fluoroscopic control. As determined, cardiopulmonary volume was not strictly limited to the heart and lungs but included a small part of the arterial system where circulation velocities should produce changes proportionate to cardiac output. This introduced only a small systemic error by proportionately increasing absolute values.

Cardiac output was determined in triplicate, at least, using indocyanine green dye $(5 \mathrm{mg}$.) introduced into the venous or atrial catheter, and then flushed into the circulation in less than a half second with $5 \mathrm{ml}$. saline. Blood was withdrawn from the arterial catheter through a Gilford densitometer, using its constant rate pump with the speed set between 0.3 and $0.5 \mathrm{ml}$. $/ \mathrm{sec}$. The delay in the sampling system could be corrected using the data of Milnor and Jose (1960), since the volume and length of our catheters never exceeded theirs. Curves were inscribed on a fast response Texas Instrument Rectiwriter recorder. Blood was reinfused immediately after the curve inscription thereby ensuring no blood loss during investigation. After each study, this system was calibrated with known dye concentrations at the same pump speed used during output determinations. Curves were calculated using a modification (Ulrych, Widimský, and Kasalický, 1966) of the principle first described by Cyvin (1950), which involves integrating the first part of the curve at one-second intervals, and calculating the area under the exponential downslope by mathematical integration. Cardiopulmonary blood volume was the product of mean transit time and blood flow per second and expressed as 1./1.73 m. ${ }^{2}$ Successive determinations of cardiac output varied by only 7 per cent (average) in the same subject (Frohlich et al., 1967).

Arterial and venous pressures were measured using Statham P 23Db transducers and recorded on a Sanborn direct-writing oscillograph. Heart rate was counted from a continuously recorded electrocardiogram.

Blood volume was estimated using radio-iodinated human serum albumin, according to the technique of Williams and Fine (1961), and expressed as $\mathrm{ml} . / 1 \cdot 73$ m. ${ }^{2}$ Haematocrit was measured in duplicate by capillary centrifugation. All samples were withdrawn from the arterial catheter to avoid possible errors caused by differences in venous haematocrit in different parts of the body.

Derived variables were calculated as follows: total peripheral resistance, by dividing mean arterial pressure by cardiac output; stroke volume, by dividing cardiac output by heart rate; and peripheral blood volume, by subtracting cardiopulmonary from total blood volume. For purposes of comparison, cardiac output, cardiopulmonary, and total blood volumes were corrected for ideal body surface area.

Statistical evaluation of results was performed by standard techniques using the t-test and correlation coefficient methods (Croxton and Cowden, 1941).

\section{RESULTS}

Despite the small number of subjects, the results were consistent with those obtained previously (Frohlich et al., 1967) (Table). Therefore this sampling can be considered to be representative of our haemodynamic experience with normal subjects, and essential and renovascular hypertensive patients (Frohlich et al., 1965, 1968). In brief, arterial blood pressure and total peripheral resistance were raised in the hypertensive groups. Resistance was higher in essential than in renovascular hypertensives, and cardiac output higher in renovascular than in essential hypertensives; total blood volumes were decreased predominantly in renovascular hypertensives. Cardiopulmonary blood volume in normotensive subjects and patients with essential and renovascular hypertension was $1.12 \quad 1 . / 1.73 \quad \mathrm{~m}^{2}$, $1.161 . / 1 \cdot 73 \mathrm{~m}^{2}$, and $1.271 . / 1.73 \mathrm{~m}^{2}$, respectively. Peripheral blood volume was significantly lower than normal in renovascular hypertensives $(p<0.05)$; there was no difference between these 7 essential hypertensives and normal subjects.

For the entire group there was a direct correlation between cardiopulmonary blood volume and cardiac output $(r=0.617 ; p<0.005)$ and stroke volume $(r=0.661 ; p<0.005)$ (Fig. 1a and b). Similarly, there was a direct correlation between the fraction of total blood volume in the heart and lungs and cardiac output $(r=0.774 ; p<0.001)$ and stroke volume $(r=0.679 ; p<0.005)$ (Fig. $2 a$ and $b)$. Because of the small numbers of subjects studied, it was not possible to make valid correlations for each diagnostic group; however, the same relation seemed to obtain.

\section{Discussion}

Cardiac output and stroke volume seem more dependent upon redistribution of intravascular volume to the cardiopulmonary circulation than on total blood volume. While both hypertensive groups had diminished total blood volume, their cardiac output differed: low-normal in essential and raised in renovascular hypertension. Nevertheless, in normals as well as essential and renovascular hypertensives, output correlated directly with the fraction of total blood volume in the cardio- 
TABLE

HAEMODYNAMIC FUNCTIONS OF NORMOTENSIVE SUBJECTS AND HYPERTENSIVE PATIENTS

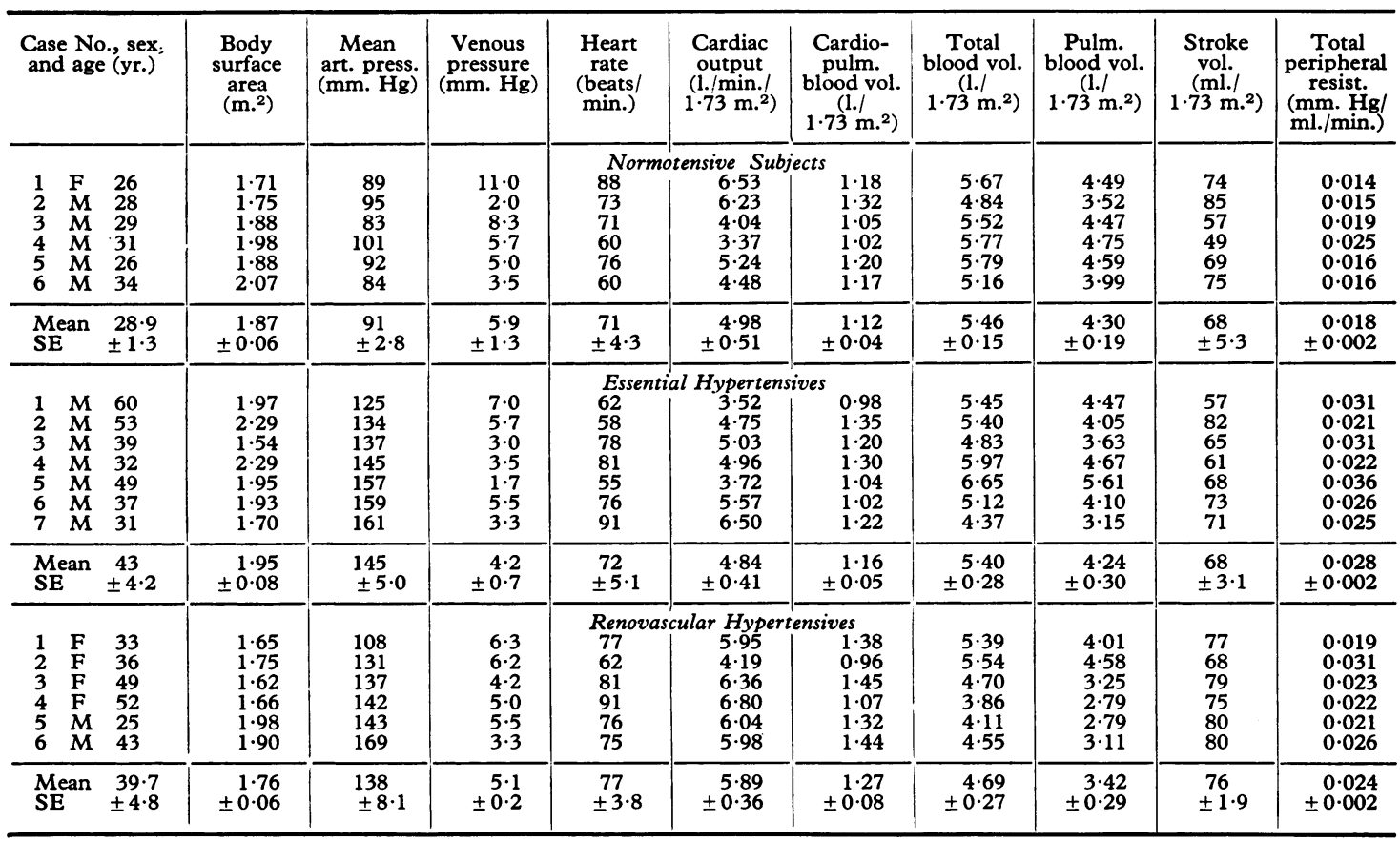

pulmonary circulation. Therefore, redistribution of blood to that area seems a major determinant of cardiac output in normal or hypertensive individuals, if the heart is not failing.

There are some discrepancies between our findings of cardiopulmonary blood volume and those of Levinson et al. (1966) and Taylor et al. (1965), but these differences can be explained by differences in procedures and methods. Thus, when our data are related to one square metre body surface area rather than $1.73 \mathrm{~m}^{2}$, the higher cardiopulmonary blood volume in our study $\left(648 \mathrm{ml} . / \mathrm{m}^{2}\right)$ might be explained because our patients were not premedicated with barbiturates. Barbiturates might alter peripheral vascular tone (Swingle and Swingle, 1963) by providing a lesser redistribution of blood from the peripheral veins to the thorax. Moreover, our cardiopulmonary blood volumes are almost identical with those of Taylor et al. $\left(500 \mathrm{ml} . / \mathrm{m} .{ }^{2}\right)$ when one takes into consideration that their measurement excluded the volume of the right atrium and ventricle. Levinson et al. (1966) carefully calculated right atrial volume to be approximately 30 $\mathrm{ml} . / \mathrm{m}^{2}$ and right ventricular volume approximately $90 \mathrm{ml} . / \mathrm{m}^{2}$ Thus, if this $120 \mathrm{ml} . / \mathrm{m} .^{2}$ were added to the $500 \mathrm{ml} . / \mathrm{m}^{2}{ }^{2}$ reported by Taylor et al.
(1965), the $620 \mathrm{ml} . / \mathrm{m}^{2}$ is in remarkable agreement with our finding of $648 \mathrm{ml} . / \mathrm{m}^{2}$

Pre-capillary vessels primarily subserve vascular resistance, not capacitance. Therefore, increased total peripheral resistance, which is primarily arterial, cannot by itself produce a shift of intravascular volume to the cardiopulmonary circulation. Theoretically, a failing left ventricle and normal right ventricle can be associated with a shift of blood into the thorax and, though pulmonary wedge pressures were not measured, it seems inconceivable that left ventricular failure might have been present in those individuals with high cardiac output and absent in those with low output.

The direct relation between cardiopulmonary volume, cardiac output, and stroke volume in both normotensive subjects and hypertensive patients is further evidence against cardiac failure in either hypertensive group. The higher cardiac output in patients with renal arterial disease is related, therefore, to a central redistribution of intravascular volume; this has occurred despite a reduction in total blood volume equivalent to that observed in patients with essential hypertension.

We speculate that a venous mechanism exists whereby intravascular volume may shift from the 

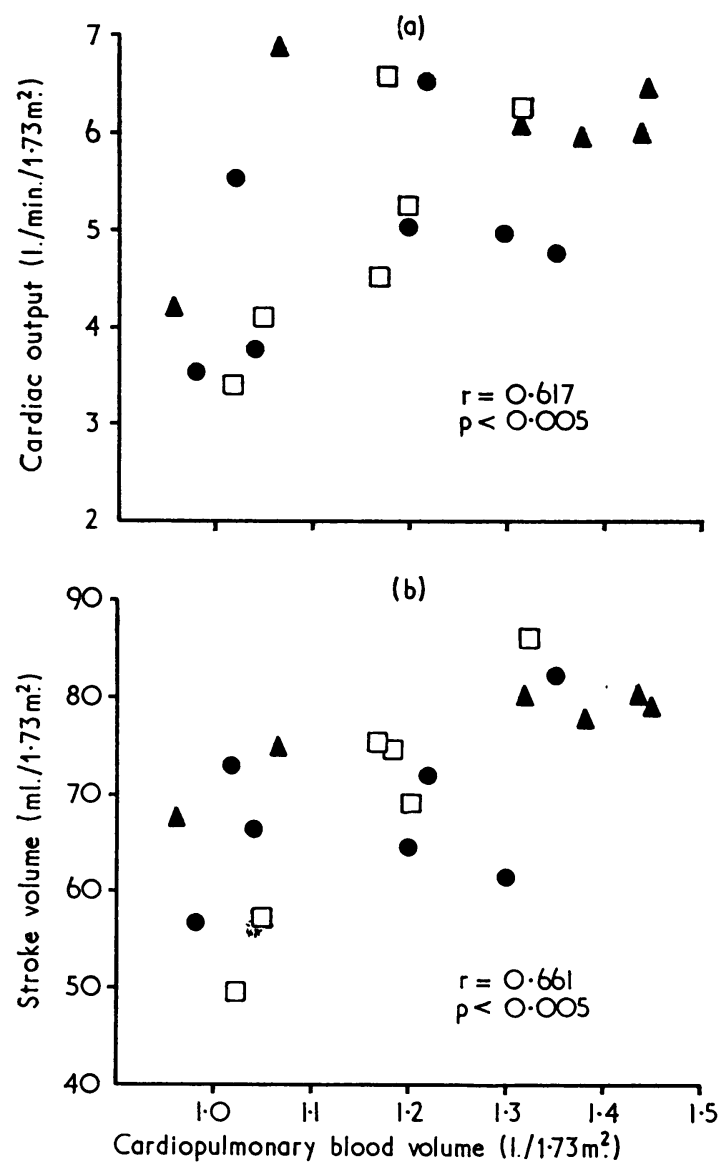

FIG. 1.-Graphs showing direct relation of cardiac output (a) and stroke volume (b) with cardiopulmonary blood volume. Symbol legend: open squares $(\square)$, normotensive subjects; closed triangles $(\Delta)$, renovascular hypertensives; closed circles $(\boldsymbol{\theta})$, essential hypertensives.

periphery to the cardiopulmonary circulation. Folkow and Mellander (1964) have shown that with small degrees of localized venoconstriction large amounts of blood can be redistributed to other capacitance beds or ultrafiltered at the capillary level. Thus, with venoconstriction, total blood volume may be reduced as a result of increased capillary hydrostatic pressure and increased plasma ultrafiltration. Differences between hypertensive groups, therefore, are not produced by intravascular volume changes but by redistribution phenomena which may be associated with the underlying causative mechanisms.

\section{SUMMARY}

The relationships of cardiopulmonary blood
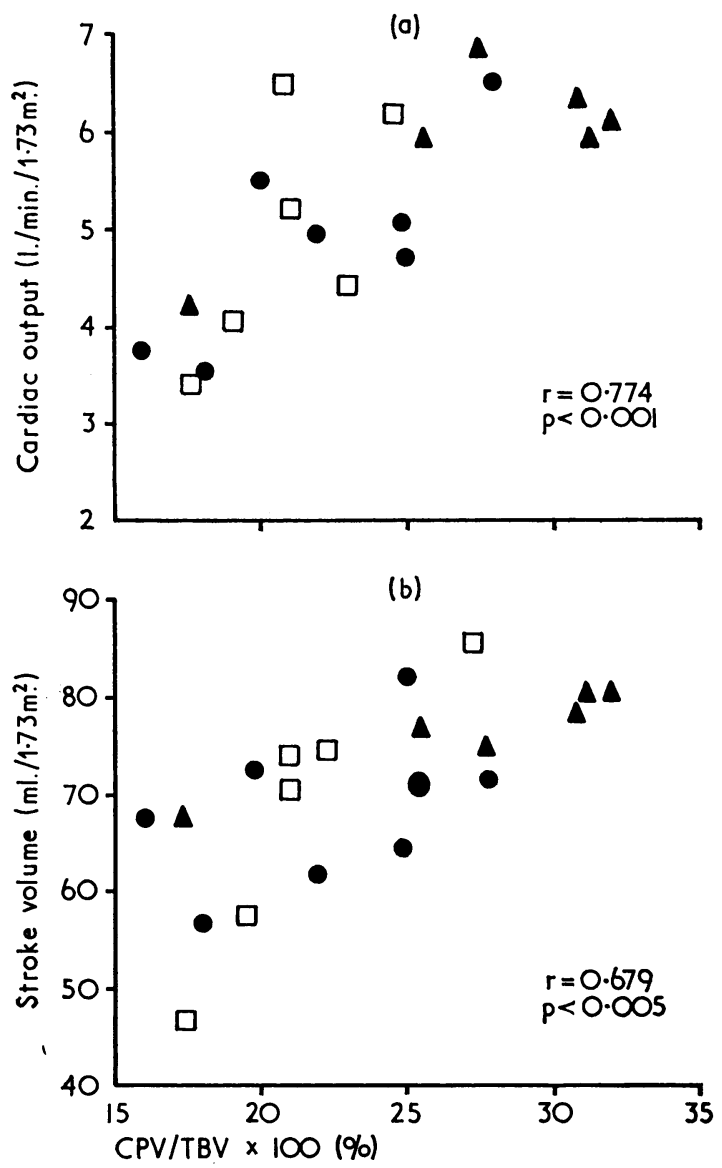

Fig. 2.-Graphs showing direct correlations of cardiac output (a) and stroke volume (b) with the fraction of total blood volume in the heart and lungs. Symbol legend: open squares $(\square)$, normotensive subjects; closed triangles $(\boldsymbol{\Delta})$, renovascular

hypertensives; closed circles $(\bullet)$, essential hypertensives.

volume to cardiac output and total blood volume were investigated in 6 normotensive subjects and 13 patients with essential or renovascular hypertension. Cardiac output and stroke volume were directly correlated with both cardiopulmonary volume and the fraction of total blood volume in the heart and lungs. Blood volume was reduced in both forms of hypertension, suggesting peripheral venoconstriction and increased capillary hydrostatic pressure. Therefore, differences in cardiac output between hypertensive groups are not produced by changes in intravascular volume, but by redistribution phenomena which may be associated with the underlying causative mechanisms.

The authors gratefully acknowledge the excellent technical assistance of Helen Kleinhenz, R.N. 


\section{REFERENCES}

Bello, C. T., Sevy, R. W., and Harakal, C. (1965). Varying hemodynamic patterns in essential hypertension. Amer. F. med. Sci., 250, 24.

Caliva, F. S., Napodano, R. J., and Lyons, R. H. (1963a). Digital hemodynamics in normotensive and hypertensive states. II. Venomotor tone. Circulation, 28, 421.

- - , Stafford, R. M., Loftus, W., and Lyons, R. H. (1963b). Digital hemodynamics in normotensive and hypertensive states. I. Digital mean arterial and venous pressures, blood flow, and vascular resistance. Circulation, 28, 415.

Croxton, F. E., and Cowden, D. J. (1941). Applied General Statistics. Prentice-Hall, New York.

Cyvin, K. (1950). Calculation of cardiac output by estimation with dilution method. Acta physiol. scand, 19, 57.

Dock, D. S., Kraus, W. L., McGuire, L. B., Hyland, J. W., Haynes, F. W., and Dexter, L. (1961). The pulmonary blood volume in man. f. clin. Invest., 40, 317.

de Freitas, F. M., Faraco, E. Z., de Azevedo, D. F., Zaduchliver, J., and Lewin, I. (1965). Behavior of normal pulmonary circulation during changes of total blood volume in man. F. clin. Invest., 44, 366.

Finkielman, S., Worcel, M., and Agrest, A. (1965). Hemodynamic patterns in essential hypertension. Circulation, 31, 356.

Folkow, B., and Mellander, S. (1964). Veins and venous tone. Amer. Heart F., 68, 397.

Frohlich, E. D., Tarazi, R. C. Ulrych, M., and Dustan, H. P. (1967). Long-term variation of cardiac output in normotensive and hypertensive men. Physiologist, 10, 174.

- Ulrych, M., Tarazi, R. C., Dustan, H. P., and Page, I. H. (1965). A hemodynamic comparison of essential and renovascular hypertension. Cardiac output and total peripheral resistance-supine and tilted patients. Circulation, 35, 289.

$\longrightarrow,-,-$ and - (1968). Hemodynamics of renal arterial diseases and hypertension. Amer. F. med. Sci., 255, 29.

Levinson, G. E., Frank, M. J., and Hellems, K. H. (1964). The pulmonary vascular volume in man: measurement from atrial dilution curves. Amer. Heart f., 67, 734.
, Pacifico, A. D., and Frank, M. J. (1966). Studies of cardiopulmonary blood volume. Circulation, 33, 347.

Milnor, W. R., and Jose, A. D. (1960). Distortion of indicator-dilution curves by sampling systems. $\mathcal{F}$. appl. Physiol., 15, 177.

$\longrightarrow,-$, and McGaff, C. J. (1960). Pulmonary vascular volume, resistance, and compliance in man. Circulation, 22, 130.

Page, I. H., and McCubbin, J. W. (1965). The physiology of arterial hypertension. In Handbook of Physiology: Section 2: Circulation, Vol. III, p. 2163. Ed. by W. F. Hamilton. American Physiological Society, Washington, D.C.

Schlant, R. C. Novack, P., Kraus, W. L., Moore, C. B., Haynes, F. W., and Dexter, L. (1959). Determination of central blood volume. Comparison of StewartHamilton method with direct measurements in dogs. Amer. F. Physiol., 196, 499.

Seldinger; S. I. (1953). Catheter replacement of the needle in percutaneous arteriography. Acta radiol. (Stockh.), $39,368$.

Swingle, W. W., and Swingle, A. J. (1963). Effect of sodium pentobarbital anesthesia on plasma volume of adrenalectomized dogs. Amer. F. Physiol., 205, 555.

Tarazi, R. C., Dustan, H. P., Frolich, E. D., and Gifford, R. W., Jr. (1969). Value of plasma volume measurement in hypertensive diseases (Abstract). $\mathcal{F}$. clin. Invest. In the press.

Taylor, S. H., Mackenzie, G. J., George, M., and McDonald, A. (1965). Effects of adrenergic blockade on the pulmonary circulation in man. Brit. Heart f., 27, 627.

Ulrych, M., Widimský, J., and Kasalický, J. (1966). Reprodukovatelnost stanoveni plicniho Krevniho objemu dilučnimi barvivovymi metodami. (Reproducibility of pulmonary blood volume determination by dye dilution techniques.) Čs. Fysiol., 15, 245.

Widimský, J., Fejfarová, M. H., and Fejfar, Z. (1957). Changes of cardiac output in hypertensive disease. Cardiologia (Basel), 31, 381.

Williams, J. A., and Fine, J. (1961). Measurement of blood volume with a new apparatus. New Engl.F. Med., 264, 842.

Wood, J. E. (1961). Peripheral venous and arterial responses to infusions of angiotensin in normal and hypertensive subjects. Circulat. Res., 9, 768. 